\title{
Blunted neural response to anticipation, effort and consummation of reward and aversion in adolescents with depression symptomatology
}

Article

Accepted Version

Rzepa, E., Fisk, J. and McCabe, C. (2017) Blunted neural response to anticipation, effort and consummation of reward and aversion in adolescents with depression symptomatology. Journal of Psychopharmacology, 31 (3). pp. 303-311. ISSN 1461-7285 doi: https://doi.org/10.1177/0269881116681416 Available at https://centaur.reading.ac.uk/67918/

It is advisable to refer to the publisher's version if you intend to cite from the work. See Guidance on citing.

To link to this article DOI: http://dx.doi.org/10.1177/0269881116681416

Publisher: Sage Publications

All outputs in CentAUR are protected by Intellectual Property Rights law, including copyright law. Copyright and IPR is retained by the creators or other copyright holders. Terms and conditions for use of this material are defined in the End User Agreement. 


\section{CentAUR}

Central Archive at the University of Reading

Reading's research outputs online 
Title:

Blunted Neural Response to Anticipation, Effort and Consummation of Reward and Aversion in Adolescents with Depression Symptomatology.

Short title:

Neural reward in adolescents with low mood.

Ewelina Rzepa MSc, Jennifer Fisk MSc, Ciara McCabe* PhD.

School of Psychology and Clinical Language Sciences, University of Reading, UK.

* Corresponding author:

Dr Ciara McCabe

Associate Professor of Neuroscience,

School of Psychology and Clinical Language Sciences,

University of Reading,

Reading RG6 6AL,

Tel: +44 1183785450

c.mccabe@ reading.ac.uk

Key words: depression, fMRI, reward, aversion, adolescents, at risk, anhedonia, biomarker.

Word count: 3767

Figures: 3

Tables: 2 
Abstract

Neural reward function has been proposed as a possible biomarker for depression. However how the neural response to reward and aversion might differ in young adolescents with current symptoms of depression is as yet unclear.

33 adolescents were recruited. 17 scoring low on the Mood and Feelings Questionnaire (MFQ) (Low Risk: LR) and 16 scoring high on the MFQ (High Risk: HR). Our fMRI task measured; anticipation (pleasant/unpleasant cue), effort (achieve a pleasant taste or avoid an unpleasant taste) and consummation (pleasant/unpleasant tastes) in Regions of Interest; ventral medial prefrontal cortex (vmPFC), pregenual cingulate cortex (pgACC), the insula and ventral striatum. We also examined whole brain group differences.

In the ROI analysis we found reduced activity in the HR group in the pgACC during anticipation and reduced pgACC and vmPFC during effort and consummation. In the whole brain analysis we also found reduced activity in the HR group in the prefrontal cortex and the precuneus during anticipation. We found reduced activity in the hippocampus during the effort phase and in the anterior cingulate/frontal pole during consummation in the HR group. Increased anhedonia measures correlated with decreased pgACC activity during consummation in the HR group only.

Our results are the first to show that adolescents with depression symptoms have blunted neural responses during the anticipation, effort and consummation of rewarding and aversive stimuli. This study suggests that interventions in young people at risk of depression, that can reverse blunted responses, might be beneficial as preventative strategies. 
Introduction

Anhedonia (loss of interest and pleasure) is one of the two main diagnostic criteria for depression (AmericanPsychiatricAssociation, 2013) and is related to 0abnormalities in the brain's reward mechanisms and suggested as a possible biomarker of risk for depression (Argyropoulos and Nutt, 2013, Nutt et al., 2007, Hasler et al., 2004). Identifying biomarkers such as the neural response to reward could help develop preventative treatments for young people at increased risk of clinical depression.

Anhedonia is multi-dimensional, with the anticipatory (appetitive/wanting) and consummatory (hedonic/liking) dimensions being the most widely examined in depression (Frey et al., 2015, McCabe, 2014, Nutt et al., 2007). Studies in depression have found reduced anticipatory and consummatory responses to reward in the ventral and dorsal striatum (Smoski et al., 2009, Forbes et al., 2009, Pizzagalli et al., 2009, Zhang et al., 2013, Epstein et al., 2006, Ubl et al., 2015)with increased activity to the anticipation of gains in the anterior cingulate (Knutson et al., 2008). However few studies investigate the separate dimensions of anhedonia within the same task (Treadway and Zald, 2011, Zhang et al., 2013). Yet a recent behavioural study suggests another possible conceptual dimension of anhedonia that of effort expenditure for reward. The authors found that effort expenditure was impaired in depressed patients (Sherdell et al., 2012, Treadway et al., 2012, Yang et al., 2014).

Interestingly the results of neural responses to aversive stimuli in depressed patients are less consistent, with some studies finding increased responses in the amygdala (Knutson and Greer, 2008, Sheline et al., 2001, Surguladze et al., 2004) 
whilst others find blunted responses in the amygdala and lateral orbitofrontal cortex (1OFC) (Bylsma et al., 2008) (Luking et al., 2015, McCabe et al., 2009). Studies that find blunted responses to both reward and aversion in depression (see meta-analysis (Bylsma et al., 2008)) however fit with the theory of Emotion Context Insensitivity (Rottenberg et al., 2005). This theory indicates a reduced reactivity to all emotion cues, regardless of valence (Rottenberg et al., 2005, Rottenberg, 2007).

To assess the neural response to reward and aversion we have developed an experimental model that examines the anticipation, effort and consummation of pleasant and unpleasant sights and tastes (Dean et al., 2016). In an attempt to examine neural biomarkers we have shown previously that participants recovered from depression have decreased responses to anticipation and consummation (sight and taste of chocolate reward) in both ventral striatum and anterior cingulate cortex (ACC) (McCabe et al., 2009). In a follow up study we examined young people (16-21 yrs.) with a family history of depression (Beardslee et al., 1998) but no personal experience of depression and found diminished neural responses in the orbitofrontal cortex (OFC) and the dorsal anterior cingulate cortex (dACC) to rewarding stimuli (McCabe et al., 2012) in the at risk group. Consistent with this a recent behavioural study found reduced risk taking in young people at increased familial risk of depression (Mannie et al., 2015).

Despite adolescence being a critical period of neural development that increases vulnerability to depression (Davey et al., 2008) studies report conflicting results regarding the direction of developmental changes (Forbes et al., 2010). Further, few studies report how current depression symptoms map onto neural responses to reward. One recent study has found that decreased ventral striatal 
responses to monetary reward predicts depressive symptoms in adolescents (Hanson et al., 2015). Thus, the aim of this study was to extend this work by investigating neural responses during reward and aversion processing (anticipation, effort and consummation) in younger adolescents (13-18 yrs.) with current depressive symptoms but no clinical diagnosis.

Materials and methods

\section{Participants}

33 participants were recruited for the study. 17 volunteers were classified as low risk (LR) and 16 volunteers as high risk (HR) for depression based on scores on the Mood and Feelings Questionnaire (MFQ) (Angold et al., 1995). The MFQ scores were $<15$ for LR and >27 for HR. Participants who scored between 15 and 27 were excluded from the study. The University of Reading Ethics approved the study and written informed consent from all participants was obtained.

Potential participants were assessed with the Structured Clinical Interview for DSM-IV Axis I Disorders Schedule (First et al., 1997) to exclude a personal current or previous history of major depression or any other Axis 1 disorder. Further no subjects had ever been diagnosed with depression or had sought treatment for depression. We also excluded pregnancy and any contraindications to MRI. With the exception of the contraceptive pill, volunteers took no medication. 
All subjects completed the: MFQ, Beck Depression Inventory (BDI; (Beck, 1961)), the Fawcett-Clarke Pleasure Scale (FCPS; (Fawcett, 1983)), the Snaith-Hamilton Pleasure Scale (SHAPS; (Snaith, 1995)), the Temporal Experience of Pleasure Scale (TEPS; (Gard D.E, 2006)), a "chocolate questionnaire" to measure liking, craving, and frequency of eating chocolate (Rolls and McCabe, 2007). Body mass index (BMI) in the normal range was part of the inclusion criteria.

\section{Overall design}

Participants were asked to refrain from consuming chocolate 24 hours prior to scanning. Before and after each scan, volunteers completed the Befindlichskeits scale (BFS) of mood and energy (von Zerssen et al., 1974) and a mood visual analogue scale (VAS).

The task was adapted from (McCabe et al., 2010) to include an effort stage. The task (40 trials) had 4 conditions based on the trial type (reward/aversive) and its level of difficulty (easy/hard). Trial type was cued by a visual stimulus (chocolate picture or picture of moldy drink (2 sec)), which indicated either to work to win the chocolate taste or to avoid the aversive taste (effort phase). Difficulty was determined by the amount of effort required to complete the effort stage (easy $=24$, hard $=45$ button presses). This required volunteers to press a button as fast as possible $(<6 \mathrm{sec})$ to move a bar towards the pleasant chocolate picture (reward) or away from the unpleasant moldy picture (aversive), allowing enough time to complete easy trials but not hard. If on reward trials volunteers were successful they received the taste $(5 \mathrm{sec}$ delivery and $2 \mathrm{sec}$ swallow cue) of chocolate and if not they received the tasteless solution. If on aversive trials volunteers were successful they received the tasteless solution and if not they received the unpleasant taste. A grey image $(2 \mathrm{sec})$ was 
presented at the end of each trial. Each condition was repeated 10 times, chosen by random permutation. Jitters were used for both interstimulus intervals and inter-trial intervals. To sustain effort, 4 trials ( 2 reward/2 aversive) were longer at $9 \mathrm{sec}$ each. Volunteers also rated 'wanting', 'pleasantness' ( +2 to -2$)$ and 'intensity' $(0$ to +4$)$ on a VAS on each trial.

\section{Stimuli}

We used a picture of liquid chocolate (reward), a moldy drink (aversive) and a grey image (control). The rewarding taste was a Belgian chocolate drink and the aversive taste was a combination of the chocolate drink mixed with beetroot juice, providing a similar texture. The tasteless solution $\left(25 \times 10^{-3} \mathrm{~mol} / \mathrm{L} \mathrm{KCL}\right.$ and $2.5 \times 10^{-}$ ${ }^{3} \mathrm{~mol} / \mathrm{L} \mathrm{NaHCO}_{3}$ in distilled $\mathrm{H}_{2} \mathrm{O}$ ) was also used as a rinse between trials. Solutions were delivered through three teflon tubes allowing $0.5 \mathrm{~mL}$ of solution to be manually delivered.

fMRI Scan

The experimental protocol consisted of an event-related interleaved design. A Siemens Magnetom Trio 3T whole-body MRI scanner and a 32-channel head coil were used. Multi-band accelerated pulse sequencing (version no. RO12, Center for Magnetic Resonance Research, University of Minnesota, USA, EPI 2D BOLD/SE/DIFF Sequence) was used with an acceleration factor of 6 . T2*-weighted echo planner imaging slices were obtained every $0.7 \mathrm{~s}$ (TR). Fifty-four axial slices with in-plane resolution of $2.4 \times 2.4 \mathrm{~mm}$ and between-plane spacing of $2.4 \mathrm{~mm}$ were attained. The matrix size was $96 \times 96$ and the field of view was $230 \times 230 \mathrm{~mm}$. Acquisition was performed during task performance, yielding 3500 volumes. An 
anatomical T1 volume with sagittal plane slice thickness $1 \mathrm{~mm}$ and in-plane resolution of $1.0 \times 1.0 \mathrm{~mm}$ was also acquired.

fMRI analysis

Statistical Parametric Mapping (SPM8) was used for realignment and normalization to the Montreal Neurological Institute (MNI) coordinate system and spatial smoothing with a 6-mm full-width-at-half-maximum Gaussian kernel and global scaling (Collins et al., 1994). The time series at each voxel was low-pass filtered with a hemodynamic response kernel. Time series non-sphericity at each voxel was estimated and corrected for (Friston et al., 2002), and a high-pass filter with a cut-off period of $128 \mathrm{sec}$ was applied.

In the single-event design, a general linear model was then applied to the time course of activation in which stimulus onsets were modeled as single impulse response functions and then convolved with the canonical hemodynamic response function (Friston et al., 1994). Linear contrasts were defined to test specific effects. Time derivatives were included in the basis functions set. Following smoothness estimation (Worsley et al., 1996), linear contrasts of parameter estimates were defined to test the specific effects of each condition (pleasant/unpleasant cue - grey image and pleasant/unpleasant taste - rinse) with each individual dataset. Voxel values for each contrast resulted in a statistical parametric map of the corresponding $t$ statistic (transformed into the unit normal distribution (SPM $z$ )). Movement parameters for each person were added as additional regressors.

Second-level fMRI analyses examined simple main effects of task with onesample $t$-tests for all scans (Table S1). Independent samples t-tests were used to examine between groups differences using SPM8. Results were thresholded at 
$p=0.001$ and whole-brain cluster corrected $[\mathrm{p}<0.05$ family-wise error $(\mathrm{FWE})$ for multiple comparisons] with age, gender and BMI added as covariates of no interest. Thresholding at $\mathrm{p}=0.001$ with a cluster threshold of $\mathrm{k}=30$ was our attempt at reducing both Type 1 and Type 11 errors in our results. Given that we have run this particular design in our previous studies we believe we are less likely to attribute real activation to noise (Type I errors are not likely to replicate across multiple studies) and more likely instead to miss effects by increasing the $\mathrm{p}$ threshold. Therefore we increase the cluster threshold to 30 in an attempt to rebalance the Type 1 and Type 11 error rate. We also think this is appropriate given that these are healthy human volunteers and so differences in reward subtype correlations might have relatively subtle effects (Lieberman and Cunningham, 2009).

We also report results from atlas-based ROI analysis in SPM8 using Wake Forest Pick Atlas Toolbox to create $8 \mathrm{~mm}$ spheres from coordinates selected from previous studies; pregenual cingulate cortex (pgACC) [3 36 2] (McCabe et al., 2009), insula [-34 14 4] (McCabe et al., 2009), ventral medial prefrontal cortex (vmPFC) [8 56 -12] (McCabe et al., 2009) and ventral striatum [10 8 -4] (Rolls and McCabe, 2007) as these regions have been found to be activated by our task. Plots of contrast estimates were extracted with plots tool in SPM8, and Wake Forest University Pick Atlas toolbox was used to display neural activation, with error bars representing the standard error of the mean.

\section{Correlations with Anhedonia measure}

Using Pearson correlations we examined the relationship between mood (anhedonia) and the extracted beta values from our significant fMRI results. 
Results

Demographic and Clinical Data

Analysis (Table 1) revealed no significant age and gender differences between LR and HR groups. There were significant differences; BMI $\mathrm{p}<0.03, \mathrm{MFQ}, \mathrm{BDI}$, SHAPS, FCPS, TEPS all $\mathrm{p}<0.02$ (Table 1).

\section{Mood, Energy and Affect Scores}

For the BFS we used a repeated measures ANOVA with within subject factor of time (before and after scan) and between subject factor of group (HR and LR). Results revealed that there was no significant main effect of time $(F(1.31)=.005 ; p=.943)$ a significant main effect of group $(F(1.31)=216.73 ; p=.002)$ and significant interaction between time (before and after scan) and group (LR and HR) $(F(1.31)=5.657 ; p=.024)$. Which meant that the HR group had lower mood than LR both before and after the scan. Further paired sample t-test analysis revealed that there was a significant difference for time in the LR group $(t(16)=-3.24 ; p=.005)$ meaning the LR group had a lower mood after the scan with no effect in the HR group $(t(15)=1.28 ; p=.221)$ (Table S1).

For the VAS we used a repeated measures ANOVA with within subject factor of time, two levels (before and after scan) and within subject factor, Emotion, on nine levels (alertness, disgust, drowsiness, sadness, happiness, anxiety, withdrawn, faint, nausea) and between subject factor of group (LR and HR). Results revealed that there was no significant main effect of time $(F(1.31)=.199 ; p=.658)$ and no significant main effect of group $(F(1.31)=2.5 ; p=.124)$. There was a significant main effect of emotion $(F(8.248)=54.75 ; p<.001)$ yet no significant interaction between the time, emotion and group $(F(8.248)=1.329 ; p=.229)$. Further paired sample t-test analysis revealed that 
there was a significant difference for emotion in LR group for disgust with increasing disgust after the scan $(t(16)=-2.615, p=.019)$ and in the LR group for drowsiness with increasing drowsiness after the $\operatorname{scan}(t(15)=-3.23 ; p=.006)$ (Table $\mathrm{S} 1$ ) but not in the HR group.

\section{Subjective Ratings of Stimuli}

Ratings of wanting, pleasantness, and intensity for the stimuli were obtained during scanning on each trial for cues and the tastes. All subjects rated chocolate taste as pleasant and the aversive taste as unpleasant (Table S2). Using repeated measures ANOVA with ratings as the first factor, three levels (wanting, pleasantness, intensity) and condition as the second factor, two levels (chocolate, aversive) and between subject factor of group (LR and HR) we found no significant main effect of group $(F(1.31)=1.1 ; p=.303)$, a significant main effect of condition $(F(1.31)=683.34$; $p<.001$ ), i.e. chocolate and aversive were rated differently and a significant effect of ratings $F(2.62)=484.64 ; p<.001$ ) as expected (Table S2) but no significant group $\mathrm{x}$ condition $x$ ratings interaction $(F(2.62)=3.68 ; p=.055)$ (Table S2).

\section{Effort}

The number of button presses as well as the time needed to complete the effort part of the task was also recorded. No significant group differences were found for the number of button presses or the time needed to complete the effort part of the study $(p>.05)$ (Table S3). 
Main Effects of Stimuli on Blood Oxygen Level-Dependent Responses

Table S4 provides a summary of the main effects of one-sample t-tests in all subjects for the anticipation, effort and consummation phases. As expected, the anticipation of the rewarding stimuli activated reward-relevant circuitry including the prefrontal cortex and striatum. The anticipation of the aversive cue activated similar areas and also the insula. Effort to achieve rewards activated the precentral gyrus and also the posterior cingulate and hippocampus. Effort to avoid aversion activated the precentral gyrus, posterior cingulate cortex, precuneus and caudate. Consummation of the pleasant chocolate taste activated the striatum, the anterior cingulate, amygdala and the hippocampus, whilst the aversive taste activated the same regions but also the insula (Table S4).

Effects of Mood on Blood Oxygen Level-Dependent Responses

\section{Anticipatory phase}

$B O L D$ responses to aversive cue

Relative to LR, the HR group exhibited less BOLD responses in the pgACC ROI (Fig 1) and the medial frontal gyrus, posterior cingulate cortex /precuneus, inferior frontal gyrus and frontal pole to the unpleasant cue during whole brain analysis (Table 2, 3). There were no group differences for the pleasant stimulus.

\section{Effort Phase}

Relative to LR, the HR group exhibited less BOLD responses in the pgACC ROI (Fig 2) and vmPFC ROI and the hippocampus for the chocolate hard trials vs. chocolate easy trials during the whole brain analysis. Relative to LR, the HR group exhibited less BOLD responses in the medial frontal gyrus, the precentral gyrus and the 
superior temporal gyrus for the chocolate hard trials vs. aversive hard trials during the whole brain analysis. Relative to LR, the HR group exhibited less BOLD responses in regions such as the central operculum, frontal pole and the superior frontal gyrus for the chocolate easy trials vs. aversive easy trials during the whole brain analysis (Table $2,3)$.

\section{Consummatory Phase}

$B O L D$ responses to chocolate taste

Relative to LR, the HR group exhibited less BOLD responses in the pgACC ROI and the vmPFC ROI (Fig 3, Table 2.)

$B O L D$ responses to aversive taste

Relative to LR, the HR group exhibited less BOLD responses in the pgACC ROI and the vmPFC ROI and in the ACC/frontal pole for the unpleasant taste during whole brain analysis (Table 2, 3).

Correlational analysis

Correlational analysis results revealed significant negative correlations between the FCPS scores and the pgACC ROI activation to the chocolate taste [8 36 2 2 ( $r=-$ $.606 ; p=.013)$ in the HR group but no significant correlation in the LR group ( $r=.144$, $\mathrm{p}=.581$ ). This shows that as the anhedonia scores increased in the HR group the brain activity in the pgACC decreased (Fig 4). 


\section{Discussion}

Our findings show blunted neural responses during anticipation, effort and consummation of rewarding and aversive stimuli despite no significant differences in behavioural responses, in adolescents with depressive symptomatology. Our results are consistent with the theory of Emotion Context Insensitivity in depression whereby reduced reactivity to positive and negative stimuli is predominant (Rottenberg, 2007, Rottenberg et al., 2005).

Specifically we found reduced response in the HR group during the anticipation of the unpleasant cue in the pgACC ROI. This region is involved in reward anticipation (Sescousse et al., 2013, Kim et al., 2010) and has been found blunted to the anticipation of reward and aversion in adults with a history of depression (McCabe et al., 2009) and in currently depressed adults (Price and Drevets, 2010, Knutson and Heinz, 2015, Smoski et al., 2009, Ubl et al., 2015, Zhang et al., 2013).

We also found decreased medial and inferior frontal gyrus activation in the HR group compared to the LR group during anticipation (aversive cue). These are regions involved in cognitive control over emotional stimuli (Ochsner and Gross, 2005, Wager et al., 2008) and found dysfunctional in volunteers with depression symptoms (Beevers et al., 2010).

Despite relatively few studies examining neural responses in adolescents at risk of depression our results, of decreased pgACC ROI is similar to that of our previous study examining young people with a parent with depression where we also found evidence of diminished ACC activity to the anticipation of reward and aversion (McCabe et al., 2012). The pgACC is claimed to be a node of communication between 
the dACC, important for error detection or attention, and the more ventral ACC implicated in emotion processing and regulation as well as salience detection (Ball et al., 2014). Aberrant neuronal activation patterns of the pgACC have been found in depressed patients (Walter et al., 2009) and in remitted depressed patients in a task combining pleasant and unpleasant experiences of music and emotional faces (Aust et al., 2013). Therefore the reduced pgACC/ACC activations in our study in the HR group during the anticipation of aversive stimuli could be a mechanism by which those at risk of depression have problems using negative information to guide appropriate actions. This in turn could lead to an increased risk of depression.

During the effort phase we found more neural activity under hard trials than easy in all subjects. Specifically we found increased hippocampus and insula activity during chocolate hard trials and increased caudate activity for aversive hard (Table S4). The hippocampus is implicated in task performance and effort (Gur et al., 1997, Pribram and McGuinness, 1975, Hosking et al., 2016) when comparing whole brain analysis between groups we found decreased activation in this region in the HR group compared to the LR group which is interesting given that we found no behavioural differences between the groups in their effort expended (Table 2). We also found decreased middle frontal gyrus (MFG) activations for hard chocolate trials versus hard aversive trials in the HR group compared to the LR group and decreased pgACC ROI for easy chocolate trials versus easy aversive trials in the HR group compared to the LR group. These are regions involved in reward processing, motor responses (Liljeholm and O'Doherty, 2012, Scholl et al., 2015) and in the avoidance of aversion (Kerr et al., 2012) and in the willingness to expend effort in cost-benefit scenarios (Green et al., 2015, Schmidt et al., 2012). As such, these regions are important in 
underlying motivation both cognitive and physical (Schmidt et al., 2012). In summary we find that brain regions involved in effortful motivation to win reward and avoid aversion are reduced in adolescents at increased risk of clinical depression.

During the consummation phase we found decreased vmPFC ROI activation and pgACC ROI activation for the chocolate taste in the HR group. The pgACC decrease was significantly correlated with increasing depression symptomatology in the HR group (Fig 4). As described above aberrant neuronal activation patterns of the pgACC have been found in depressed patients (Walter et al., 2009) and in remitted depressed patients in a task combining pleasant and unpleasant experiences of music and emotional faces (Aust et al., 2013). Thus our decreased pgACC activations to chocolate taste may indicate a biological marker of difficulty engaging with the experiences of reward. The vmPFC is reported as important for hedonic processes in many studies in animals and humans and is thought to mediate internally driven motivational processes such as satiety (Bouret and Richmond, 2010, Robbins and Everitt, 1996). In our previous study of those with a history of depression we found decreased responses in vmPFC to the consummation of chocolate (McCabe et al., 2009), similar to our current results and supporting the notion that neural deficits to reward also predate clinical depression onset.

We also found decreased pgACC and vmPFC ROI activations for the aversive taste in the HR group, which is interesting given that reports in the depression literature assume elevated responses to aversive stimuli (Rottenberg et al., 2005). Further increased activity in regions like the vmPFC (part of the Default Mode Network) have been reported in the processing of fear in depression (Grimm et al., 
2009). However studies also report blunted responses to a variety of negative and positive stimuli in depressed patients with a recent meta-analysis being the first quantitative review of emotional reactivity finding that depression involves consistent reductions in both positive AND negative reactivity (Bylsma et al., 2008). Our result of blunted responses to positive and negative stimuli is also similar to our previous study with a recovered depressed sample (McCabe et al., 2009), suggesting that blunted aversion might also be a biomarker detectable both before depression onset and a residual trait marker of depression.

Interestingly we did not find either ROI or whole brain differences between the groups in the ventral striatum which is consistent with our previous study examining young people at familial risk of depression but no personal depression experiences (McCabe et al 2012). Also our results are unlike the large differences in striatal response to reward found in our previous study examining those recovered from depression (McCabe 2009). This suggests that perhaps striatal differences (in this task) are only detectable after having experienced clinical depression and is thus a state rather than a trait marker of depression. Further longitudinal studies are necessary to clarify this.

In conclusion, our results show that adolescents with depression symptomatology have reduced neural responses to both reward and aversion. This is in line with the Emotion Context Insensitivity Theory of depression whereby depression is characterised by an emotional flattening to all stimuli both positive and negative. This study suggests that there are biological markers of depression symptoms before clinical onset that may improve diagnosis and be important targets for early treatment interventions. Further, longitudinal studies with larger sample sizes are needed to clarify and replicate these results. Examining other groups at risk 
of depression such as those with a family history are needed to identify how reward function interacts with heritability, prognosis and treatment outcome in those who develop depression. 


\section{Acknowledgments/Funding}

This work has been supported by University of Reading start up fund for Dr McCabe.

\section{Conflict of Interest:}

Dr McCabe has acted as a consultant to Givaudan, GWpharma and the British Broadcasting Company (BBC) and Channel 4. Ewelina Rzepa and Jennifer Fisk report no biomedical financial interests or potential conflicts of interest. 
References:

AMERICANPSYCHIATRICASSOCIATION 2013. Diagnostic and statistical manual of mental disorders (DSM-5®), American Psychiatric Pub.

ANGOLD, A., COSTELLO, E. J., MESSER, S. C. \& PICKLES, A. 1995. Development of a short questionnaire for use in epidemiological studies of depression in children and adolescents. International journal of methods in psychiatric research.

ARGYROPOULOS, S. V. \& NUTT, D. J. 2013. Anhedonia revisited: is there a role for dopamine-targeting drugs for depression? Journal of psychopharmacology, 27, 869-77.

AUST, S., FILIP, K., KOELSCH, S., GRIMM, S. \& BAJBOUJ, M. 2013. Music in depression: Neural correlates of emotional experience in remitted depression. World J Psychiatry, 3, 8-17.

BALL, T. M., STEIN, M. B. \& PAULUS, M. P. 2014. Toward the application of functional neuroimaging to individualized treatment for anxiety and depression. Depression and anxiety, 31, 920-933.

BEARDSLEE, W. R., VERSAGE, E. M. \& GLADSTONE, T. R. 1998. Children of affectively ill parents: a review of the past 10 years. J Am Acad Child Adolesc Psychiatry, 37, 1134-41.

BECK, A. T., WARD, C. H., MENDELSON, M., MOCK, J., \& ERBAUGH, J. 1961. An inventory for measuring depression. Archives of General Psychiatry, 561571.

BEEVERS, C. G., CLASEN, P., STICE, E. \& SCHNYER, D. 2010. Depression symptoms and cognitive control of emotion cues: a functional magnetic resonance imaging study. Neuroscience, 167, 97-103.

BOURET, S. \& RICHMOND, B. J. 2010. Ventromedial and orbital prefrontal neurons differentially encode internally and externally driven motivational values in monkeys. J Neurosci, 30, 8591-601.

BYLSMA, L. M., MORRIS, B. H. \& ROTTENBERG, J. 2008. A meta-analysis of emotional reactivity in major depressive disorder. Clin Psychol Rev, 28, 676-91.

COLLINS, D. L., NEELIN, P., PETERS, T. M. \& EVANS, A. C. 1994. Automatic 3D intersubject registration of MR volumetric data in standardized Talairach space. Journal of Computer Assisted Tomography, 18, 192-205.

DAVEY, C. G., YÜCEL, M. \& ALLEN, N. B. 2008. The emergence of depression in adolescence: development of the prefrontal cortex and the representation of reward. Neuroscience \& Biobehavioral Reviews, 32, 1-19.

DEAN, Z., HORNDASCH, S., GIANNOPOULOS, P. \& MCCABE, C. 2016. Enhanced neural response to anticipation, effort and consummation of reward and aversion during bupropion treatment. Psychol Med, 46, 2263-74.

EPSTEIN, J., PAN, H., KOCSIS, J. H., YANG, Y., BUTLER, T., CHUSID, J., HOCHBERG, H., MURROUGH, J., STROHMAYER, E., STERN, E. \& SILBERSWEIG, D. A. 2006. Lack of ventral striatal response to positive stimuli in depressed versus normal subjects. Am J Psychiatry, 163, 1784-90.

FAWCETT, J., CLARK, D.C., SCHEFTNER, W. A., GIBBONS, R.D. 1983. Assessing Anhedonia in Psychiatric Patients 
The Pleasure Scale. Archives of General Psychiatry, 79-84.

FIRST, M. B., SPITZER, R. L., GIBBON, M. \& WILLIAMS, J. B. W. 1997. Structured Clinical Interview for DSM-IV Axis I Disorders: Clinical Version, . American Psychiatric Press, Washington, DC

FORBES, E. E., HARIRI, A. R., MARTIN, S. L., SILK, J. S., MOYLES, D. L., FISHER, P. M., BROWN, S. M., RYAN, N. D., BIRMAHER, B., AXELSON, D. A. \& DAHL, R. E. 2009. Altered striatal activation predicting real-world positive affect in adolescent major depressive disorder. Am J Psychiatry, 166, 64-73.

FORBES, E. E., RYAN, N. D., PHILLIPS, M. L., MANUCK, S. B., WORTHMAN, C. M., MOYLES, D. L., TARR, J. A., SCIARRILLO, S. R. \& DAHL, R. E. 2010. Healthy adolescents' neural response to reward: associations with puberty, positive affect, and depressive symptoms. Journal of the American Academy of Child \& Adolescent Psychiatry, 49, 162-172. e5.

FREY, A.-L., MALINOWSKA, L., HARLEY, K., SALHI, L., IQBAL, S., SHARMA, S. \& MCCABE, C. 2015. Investigating subtypes of reward processing deficits as trait markers for depression. Translational Developmental Psychiatry, 3.

FRISTON, K. J., GLASER, D. E., HENSON, R. N., KIEBEL, S., PHILLIPS, C. \& ASHBURNER, J. 2002. Classical and Bayesian inference in neuroimaging: applications. Neuroimage, 16, 484-512.

FRISTON, K. J., WORSLEY, K. J., FRACKOWIAK, R. S. J., MAZZIOTTA, J. C. \& EVANS, A. C. 1994. Assessing the significance of focal activations using their spatial extent. Human Brain Mapping, 1, 214-220.

GARD D.E, G. M. G., KRING A.M, JOHN O.P 2006. Anticipatory and consummatory components of the experience of pleasure: A scale development study. Journal of Research in Personality, 1086-1102.

GREEN, M. F., HORAN, W. P., BARCH, D. M. \& GOLD, J. M. 2015. Effort-based decision making: a novel approach for assessing motivation in schizophrenia. Schizophrenia bulletin, sbv071.

GRIMM, S., BOESIGER, P., BECK, J., SCHUEPBACH, D., BERMPOHL, F., WALTER, M., ERNST, J., HELL, D., BOEKER, H. \& NORTHOFF, G. 2009. Altered negative BOLD responses in the default-mode network during emotion processing in depressed subjects. Neuropsychopharmacology, 34, 932-43.

GUR, R. C., RAGLAND, J. D., MOZLEY, L. H., MOZLEY, P. D., SMITH, R., ALAVI, A., BILKER, W. \& GUR, R. E. 1997. Lateralized changes in regional cerebral blood flow during performance of verbal and facial recognition tasks: correlations with performance and "effort". Brain and Cognition, 33, 388414.

HANSON, J. L., HARIRI, A. R. \& WILLIAMSON, D. E. 2015. Blunted ventral striatum development in adolescence reflects emotional neglect and predicts depressive symptoms. Biological Psychiatry.

HASLER, G., DREVETS, W. C., MANJI, H. K. \& CHARNEY, D. S. 2004. Discovering endophenotypes for major depression. Neuropsychopharmacology, 29, 1765-81.

HOSKING, J. G., COCKER, P. J. \& WINSTANLEY, C. A. 2016. Prefrontal cortical inactivations decrease willingness to expend cognitive effort on a rodent cost/benefit decision-making task. Cerebral Cortex, 26, 1529-1538.

KERR, D. L., MCLAREN, D. G., MATHY, R. M. \& NITSCHKE, J. B. 2012. Controllability modulates the anticipatory response in the human ventromedial prefrontal cortex. Frontiers in psychology, 3. 
KIM, H., SHIMOJO, S. \& O'DOHERTY, J. P. 2010. Overlapping responses for the expectation of juice and money rewards in human ventromedial prefrontal cortex. Cerebral cortex, bhq145.

KNUTSON, B., BHANJI, J. P., COONEY, R. E., ATLAS, L. Y. \& GOTLIB, I. H. 2008. Neural responses to monetary incentives in major depression. Biol Psychiatry, 63, 686-92.

KNUTSON, B. \& GREER, S. M. 2008. Anticipatory affect: neural correlates and consequences for choice. Philos Trans R Soc Lond B Biol Sci, 363, 3771-86.

KNUTSON, B. \& HEINZ, A. 2015. Probing psychiatric symptoms with the monetary incentive delay task. Biol. Psychiatry, 77, 418-420.

LIEBERMAN, M. D. \& CUNNINGHAM, W. A. 2009. Type I and Type II error concerns in fMRI research: re-balancing the scale. Social cognitive and affective neuroscience, nsp052.

LILJEHOLM, M. \& O'DOHERTY, J. P. 2012. Contributions of the striatum to learning, motivation, and performance: an associative account. Trends in cognitive sciences, 16, 467-475.

LUKING, K. R., NEIMAN, J. S., LUBY, J. L. \& BARCH, D. M. 2015. Reduced Hedonic Capacity/Approach Motivation Relates to Blunted Responsivity to Gain and Loss Feedback in Children. J Clin Child Adolesc Psychol, 1-13.

MANNIE, Z. N., WILLIAMS, C., BROWNING, M. \& COWEN, P. J. 2015. Decision making in young people at familial risk of depression. Psychol Med, 45, 375-80.

MCCABE, C. 2014. Neural correlates of anhedonia as a trait marker for depression. Anhedonia: A Comprehensive Handbook Volume II. Springer.

MCCABE, C., COWEN, P. J. \& HARMER, C. J. 2009. Neural representation of reward in recovered depressed patients. Psychopharmacology (Berl), 205, 667-77.

MCCABE, C., MISHOR, Z., COWEN, P. J. \& HARMER, C. J. 2010. Diminished neural processing of aversive and rewarding stimuli during selective serotonin reuptake inhibitor treatment. Biol Psychiatry, 67, 439-45.

MCCABE, C., WOFFINDALE, C., HARMER, C. J. \& COWEN, P. J. 2012. Neural Processing of Reward and Punishment in Young People at Increased Familial Risk of Depression. Biological psychiatry.

NUTT, D., DEMYTTENAERE, K., JANKA, Z., AARRE, T., BOURIN, M., CANONICO, P. L., CARRASCO, J. L. \& STAHL, S. 2007. The other face of depression, reduced positive affect: the role of catecholamines in causation and cure. $J$ Psychopharmacol, 21, 461-71.

OCHSNER, K. N. \& GROSS, J. J. 2005. The cognitive control of emotion. Trends Cogn Sci, 9, 242-9.

PIZZAGALLI, D. A., HOLMES, A. J., DILLON, D. G., GOETZ, E. L., BIRK, J. L., BOGDAN, R., DOUGHERTY, D. D., IOSIFESCU, D. V., RAUCH, S. L. \& FAVA, M. 2009. Reduced caudate and nucleus accumbens response to rewards in unmedicated individuals with major depressive disorder. Am J Psychiatry, 166, 702-10.

PRIBRAM, K. H. \& MCGUINNESS, D. 1975. Arousal, activation, and effort in the control of attention. Psychological review, 82, 116.

PRICE, J. L. \& DREVETS, W. C. 2010. Neurocircuitry of mood disorders. Neuropsychopharmacology, 35, 192-216.

ROBBINS, T. W. \& EVERITT, B. J. 1996. Neurobehavioural mechanisms of reward and motivation. Curr Opin Neurobiol, 6, 228-36. 
ROLLS, E. T. \& MCCABE, C. 2007. Enhanced affective brain representations of chocolate in cravers vs. non-cravers. Eur J Neurosci, 26, 1067-76.

ROTTENBERG, J. 2007. Major depressive disorder: Emerging evidence for emotion context insensitivity. , Washington, D.C, APA Books.

ROTTENBERG, J., GROSS, J. J. \& GOTLIB, I. H. 2005. Emotion context insensitivity in major depressive disorder. J Abnorm Psychol, 114, 627-39.

SCHMIDT, L., LEBRETON, M., CLÉRY-MELIN, M.-L., DAUNIZEAU, J. \& PESSIGLIONE, M. 2012. Neural mechanisms underlying motivation of mental versus physical effort. PLoS Biol, 10, e1001266.

SCHOLL, J., KOLLING, N., NELISSEN, N., WITTMANN, M. K., HARMER, C. J. \& RUSHWORTH, M. F. 2015. The Good, the Bad, and the Irrelevant: Neural Mechanisms of Learning Real and Hypothetical Rewards and Effort. The Journal of Neuroscience, 35, 11233-11251.

SESCOUSSE, G., CALDÚ, X., SEGURA, B. \& DREHER, J.-C. 2013. Processing of primary and secondary rewards: a quantitative meta-analysis and review of human functional neuroimaging studies. Neuroscience \& Biobehavioral Reviews, 37, 681-696.

SHELINE, Y. I., BARCH, D. M., DONNELLY, J. M., OLLINGER, J. M., SNYDER, A. Z. \& MINTUN, M. A. 2001. Increased amygdala response to masked emotional faces in depressed subjects resolves with antidepressant treatment: an fMRI study. Biol Psychiatry, 50, 651-8.

SHERDELL, L., WAUGH, C. E. \& GOTLIB, I. H. 2012. Anticipatory pleasure predicts motivation for reward in major depression. J Abnorm Psychol, 121, 51-60.

SMOSKI, M. J., FELDER, J., BIZZELL, J., GREEN, S. R., ERNST, M., LYNCH, T. R. \& DICHTER, G. S. 2009. fMRI of alterations in reward selection, anticipation, and feedback in major depressive disorder. J Affect Disord, 118, 69-78.

SNAITH, R. P., HAMILTON, M., MORLEY, S., HUMAYAN, A., HARGREAVES, D., TRIGWELL, P. 1995. A scale for the assessment of hedonic tone the Snaith-Hamilton Pleasure Scale. British Journal of Psychiatry, 99-103.

SURGULADZE, S. A., YOUNG, A. W., SENIOR, C., BREBION, G., TRAVIS, M. J. \& PHILLIPS, M. L. 2004. Recognition accuracy and response bias to happy and sad facial expressions in patients with major depression. Neuropsychology, 18, 212-8.

TREADWAY, M. T., BOSSALLER, N. A., SHELTON, R. C. \& ZALD, D. H. 2012. Effortbased decision-making in major depressive disorder: a translational model of motivational anhedonia. J Abnorm Psychol, 121, 553-8.

TREADWAY, M. T. \& ZALD, D. H. 2011. Reconsidering anhedonia in depression: lessons from translational neuroscience. Neuroscience and biobehavioral reviews, 35, 537-55.

UBL, B., KUEHNER, C., KIRSCH, P., RUTTORF, M., DIENER, C. \& FLOR, H. 2015. Altered neural reward and loss processing and prediction error signalling in depression. Soc Cogn Affect Neurosci, 10, 1102-12.

VON ZERSSEN, D., STRIAN, F. \& SCHWARZ, D. 1974. Evaluation of depressive states, especially in longitudinal studies. Modern Problems of Pharmacopsychiatry, 7, 189-202.

WAGER, T. D., DAVIDSON, M. L., HUGHES, B. L., LINDQUIST, M. A. \& OCHSNER, K. N. 2008. Prefrontal-subcortical pathways mediating successful emotion regulation. Neuron, 59, 1037-50. 
WALTER, M., HENNING, A., GRIMM, S., SCHULTE, R. F., BECK, J., DYDAK, U., SCHNEPF, B., BOEKER, H., BOESIGER, P. \& NORTHOFF, G. 2009. The relationship between aberrant neuronal activation in the pregenual anterior cingulate, altered glutamatergic metabolism, and anhedonia in major depression. Archives of General Psychiatry, 66, 478-486.

WORSLEY, K. J., MARRETT, P., NEELIN, A. C., FRISTON, K. J. \& EVANS, A. C. 1996. A unified statistical approach for determining significant signals in images of cerebral activation. . Human Brain Mapping, 4, 58:73.

YANG, X. H., HUANG, J., ZHU, C. Y., WANG, Y. F., CHEUNG, E. F., CHAN, R. C. \& XIE, G. R. 2014. Motivational deficits in effort-based decision making in individuals with subsyndromal depression, first-episode and remitted depression patients. Psychiatry Res, 220, 874-82.

ZHANG, W. N., CHANG, S. H., GUO, L. Y., ZHANG, K. L. \& WANG, J. 2013. The neural correlates of reward-related processing in major depressive disorder: a meta-analysis of functional magnetic resonance imaging studies. J Affect Disord, 151, 531-9. 
Legends:

Figure 1. Anticipation: Aversive cue, left panel, axial, sagittal and coronal image of pgACC activation in LR vs. HR $(z=2.98, p=0.036$; ROI analysis with WFU Pick Atlas); right panel, contrast estimates for pgACC centered at [4 44 2].

Figure 2. Effort: Choc Easy-Aversive Easy, left panel, axial, sagittal and coronal image of pgACC activation in LR vs. HR $(z=3.13, p=0.026$; ROI analysis with WFU Pick Atlas); right panel, contrast estimates for pgACC centered at [0 36 4]. Far right panel, contrast estimates for HR and LR separately for choc easy and aversive easy.

Figure 3. Consummation: Chocolate Taste, left panel, axial, sagittal and coronal image of vmPFC activation in LR vs. HR $(z=3.08, p=0.016$; ROI analysis with WFU Pick Atlas); right panel, contrast estimates for vmPFC centered at [6 50 -8].

Figure 4. Correlations between pgACC activation to chocolate taste and anhedonia measures (FCPS) in the HR group ( $r=-.606, p=.013)$ and LR group $(r=.144, p=.581)$. 
Table 1: Demographics

\begin{tabular}{|c|c|c|c|}
\hline Measure & $\begin{array}{l}\text { HR }(n=16) \text { Mean } \\
(\mathrm{SD})\end{array}$ & $\begin{array}{l}\text { LR }(n=17) \text { Mean } \\
(\mathrm{SD})\end{array}$ & $p$-value \\
\hline Age (years) & $16.63(1.21)$ & $16.24(1.6)$ & .438 \\
\hline Gender (male) & $4 / 12$ & $6 / 11$ & .535 \\
\hline BMI & $22.08(2.6)$ & $20.25(2.1)$ & .033 \\
\hline MFQ & $40.75(6.14)$ & $4.71(5.13)$ & $<.001$ \\
\hline BDI & $30.31(12.95)$ & $2.24(4.25)$ & $<.001$ \\
\hline FCPS & $120.13(18.85)$ & $137.76(21.9)$ & .019 \\
\hline SHAPS & $30.44(5.57)$ & $4.8(5.57)$ & $<.001$ \\
\hline TEPS & $65.25(9.2)$ & $83.65(10.11)$ & $<.001$ \\
\hline $\begin{array}{l}\text { Chocolate } \\
\text { craving }\end{array}$ & $6.44(1.62)$ & $5.97(2.01)$ & .471 \\
\hline liking & $8.63(1.02)$ & $7.85(1.5)$ & .096 \\
\hline frequency & $1.93(1.52)$ & $2.47(2)$ & .396 \\
\hline
\end{tabular}


Table 2: Significant group differences from ROI analysis using WFU Pick Atlas.

\begin{tabular}{cccccc}
\hline ROI & $\mathrm{X}$ & $\mathrm{Y}$ & $\mathrm{Z}$ & $\mathrm{Z}$-score & $\mathrm{P}$ value \\
\hline $\begin{array}{c}\text { Anticipation } \\
\text { Aversive cue } \\
\text { pgACC }\end{array}$ & 4 & 44 & 2 & 2.98 & 0.036 \\
& & & & & \\
$\begin{array}{c}\text { Effort } \\
\text { Chocolate easy- }\end{array}$ & & & & & \\
Aversive easy & & & & & \\
pgACC & 0 & 36 & 4 & 3.13 & 0.026 \\
vmPFC & 10 & 6 & -4 & 3.03 & 0.034
\end{tabular}

\section{Consummation}

Chocolate taste

$\begin{array}{lllllc}\operatorname{pgACC} & 8 & 36 & 2 & 3.06 & 0.03 \\ \text { vmPFC } & 6 & 50 & -8 & 3.08 & 0.016\end{array}$

Mould taste

$\begin{array}{llcccc}\operatorname{pgACC} & 8 & 34 & 0 & 4.03 & 0.001 \\ \text { vmPFC } & 8 & 56 & -12 & 3.06 & 0.016\end{array}$

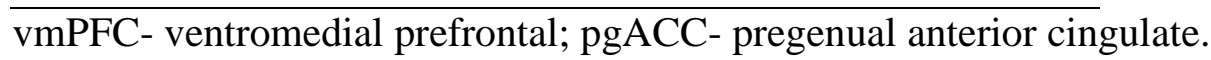

Family Wise Error corrected $\mathrm{p}<0.05$ for multiple comparisons. 
Table 3. Regions showing significant effect of mood of each of the groups on each of the conditions covaried for age, gender and BMI.

\section{MNI coordinates}

\begin{tabular}{lllllll}
\hline Brain Region & $X$ & $Y$ & $Z$ & $Z$-value & $P$-value
\end{tabular}

\section{Anticipatory}

Aversive cue: $L R>H R$

\begin{tabular}{lccccc} 
MFG & 48 & 32 & 36 & 4.56 & $<.001$ \\
IFG & 54 & 22 & 26 & 4.34 & $<.001^{\circ}$ \\
Frontal Pole & 14 & 44 & 48 & 4.16 & $<.001$ \\
PCC/Precuneus & 6 & -34 & 40 & 3.47 & $<.001$ \\
& & & & & \\
\hline
\end{tabular}

\section{Effort}

Chocolate hard-chocolate easy:

\section{$L R>H R$}

Hippocampus

$\begin{array}{lllll}-26 & -38 & 6 & 3.98 & =0.002^{\circ}\end{array}$

Chocolate hard-aversive hard:

$L R>H R$

MFG

$\begin{array}{lllll}-52 & 18 & 38 & 3.55 & <.001^{\circ}\end{array}$

Precentral gyrus

$\begin{array}{lllll}60 & -2 & 32 & 3.43 & <.001^{\circ}\end{array}$

STG

$\begin{array}{lllll}56 & -4 & -8 & 3.39 & <.001^{\circ}\end{array}$


Chocolate easy-aversive easy: $L R>H R$

$\begin{array}{lccccc}\text { Central operculum } & -54 & -8 & 20 & 4.05 & <.001 \\ \text { Frontal Pole } & -12 & 62 & 26 & 3.30 & <.001 \\ & & & & & \\ \text { SFG } & 20 & 30 & 50 & 3.15 & <.001\end{array}$

\section{Consummatory}

Aversive taste: $L R>H R$

$\begin{array}{llllll}\text { ACC/Frontal Pole } & 14 & 44 & 32 & 3.33 & =0.04\end{array}$

Thresholded $\mathrm{p}=0.001$. C- cortex; 1OFC- lateral orbitofrontal; vmPFC- ventromedial prefrontal; PCC- posterior cingulate; ACC- anterior cingulate; sgACC subgenual anterior cingulate, pgACC- pregenual anterior cingulate; MFG- middle frontal gyrus; IFG- inferior frontal gyrus; SFG- superior frontal gyrus; STG- superior temporal Gyrus.

Family Wise Error corrected $\mathrm{p}<0.05$ for multiple comparisons.

Results that don't survive MFQ as a covariate- ${ }^{\circ}$. 

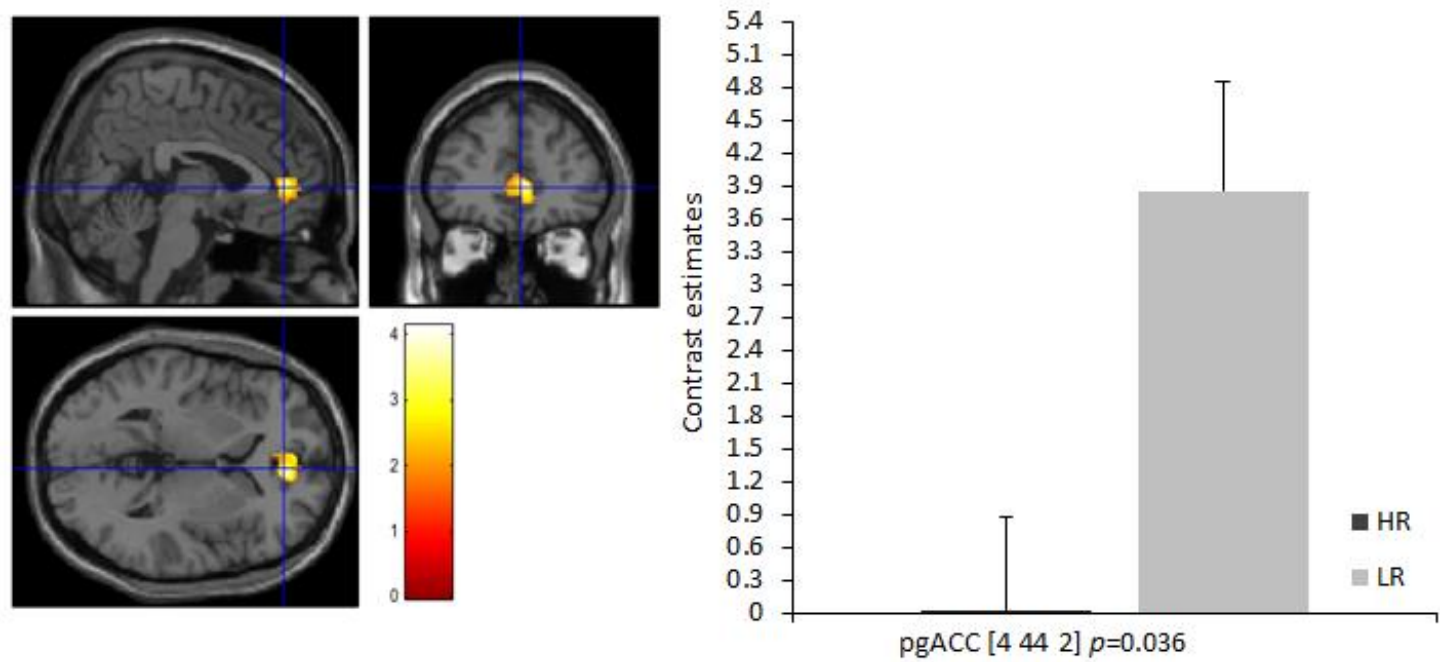

Figure 1. Anticipation: Aversive cue, left panel, axial, sagittal and coronal image of pgACC activation in LR vs. HR $(z=2.98, p=0.036$; ROI analysis with WFU pick atlas); right panel, contrast estimates for pgACC centered at [4 44 2].
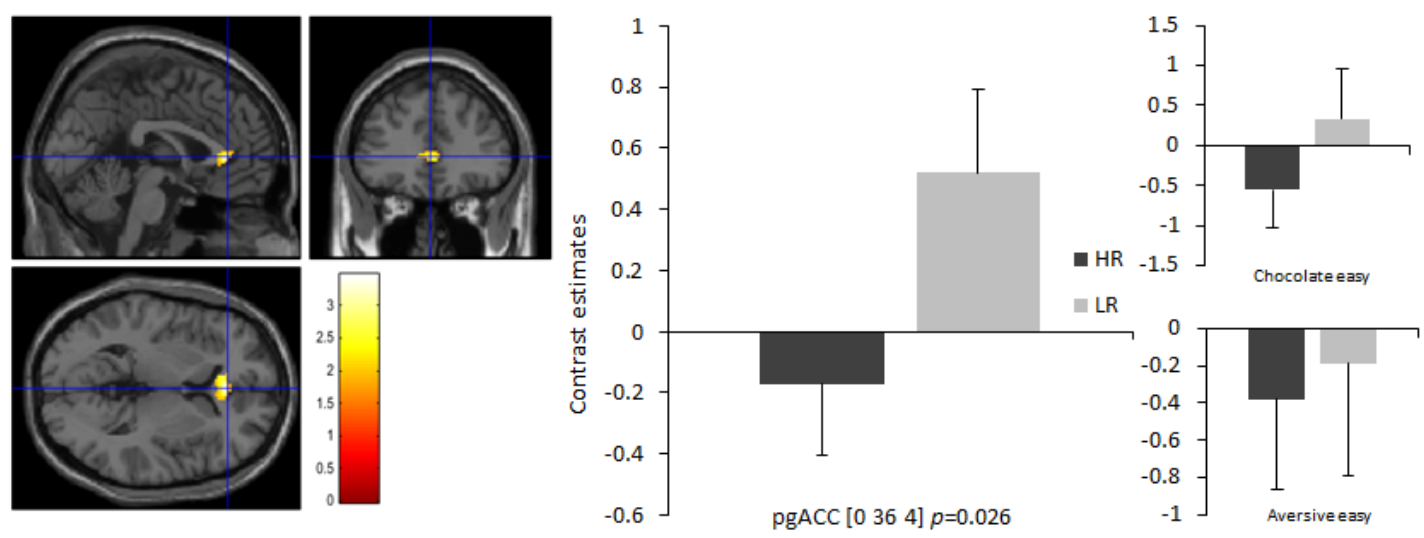

Figure 2. Effort: Choc Easy-Aversive Easy, left panel, axial, sagittal and coronal image of pgACC activation in LR vs. HR ( $\mathrm{z}=3.13, \mathrm{p}=0.026$; ROI analysis with WFU pick atlas); right panel, contrast estimates for pgACC centered at [0 36 4]. Far right panel, contrast estimates for HR and LR separately for choc easy and aversive easy. 

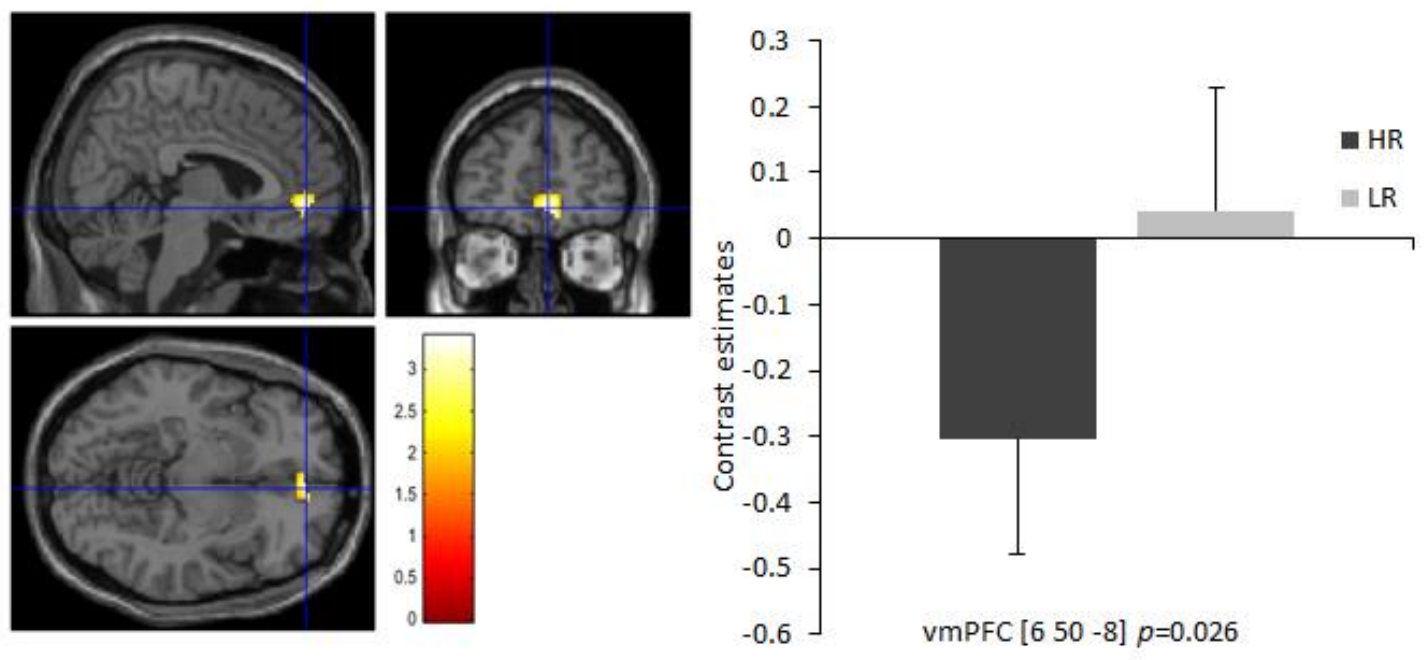

Figure 3. Consummation: Chocolate Taste, left panel, axial, sagittal and coronal image of vmPFC activation in LR vs. HR $(Z=3.08, p=0.016$; ROI analysis with WFU pick atlas); right panel, contrast estimates for vmPFC centered at [6 50 -8].

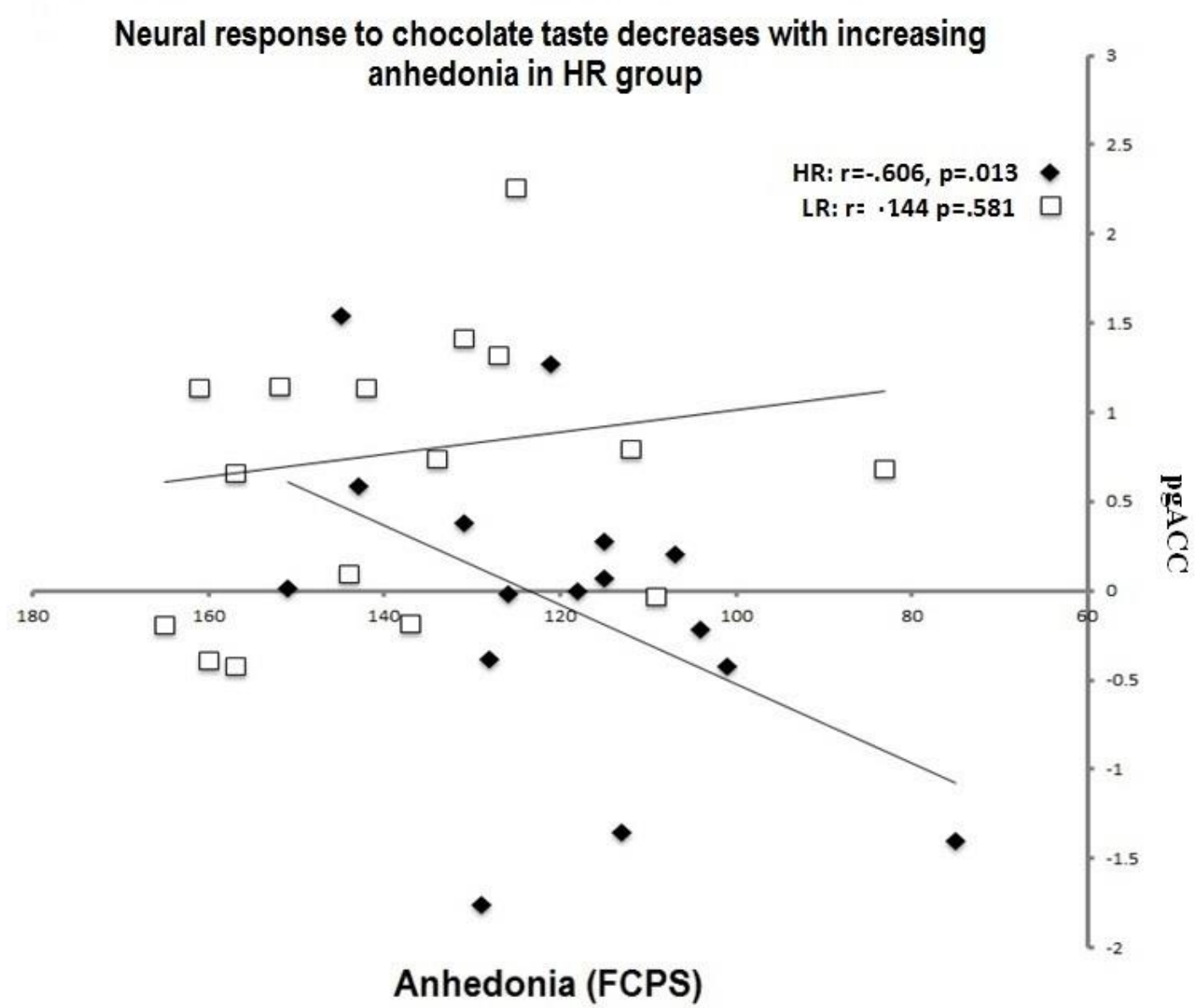

Figure 4. Correlations between pgACC activation to chocolate taste and anhedonia measures (FCPS) in the HR group $(\mathrm{r}=-.606, \mathrm{p}=.013)$ and LR group $(\mathrm{r}=.144, \mathrm{p}=.581)$. 
